\title{
Determinantes de la migración en Centroamérica Y RePÚBliCA DOMINICANA
}

\author{
Yulisa M. BENZÁN BENZÁN ${ }^{1}$
}

Recibido: 12/2/2021 • Aceptado: 01/09/2021

Cómo citar: Benzán Benzán, Y. M. (2021). Determinantes de la migración en Centroamérica y República Dominicana. Ciencia, Economía y Negocios, 5(2), 5-38. Doi: https://doi.org/10.22206/ceyn.2021.v5i2.pp5-38

\section{Resumen}

Se realiza un análisis integral de las causas y determinantes de la migración internacional en Belice, Costa Rica, El Salvador, Guatemala, Honduras, Nicaragua, Panamá y la República Dominicana, paises miembros del Sistema de la Integración Centroamericana (SICA). Especificamente, se emplea un modelo de datos de panel estimado por efectos aleatorios, que abarca el periodo 1990-2015, en el cual se plantea la verificación de las principales hipótesis sugeridas en la literatura relacionadas a factores económicos, geográficos, sociales, comerciales, politicos y culturales asociados a la migración. Los resultados sugieren que la percepción de ingresos promedios más altos, aproximado por las diferencias salariales entre ambos países, por sí sola no resulta suficiente para explicar la emigración de la región, sin embargo, constituye el determinante estructural más importante cuando se toman en consideración variables del tipo social, politico y cultural. Asimismo, la población tiende a emigrar a países que garanticen una vida más longeva, pero también a sociedades más desiguales en términos económicos. La inseguridad o percepción de riesgo en el pais de destino y un mayor fujo de inversión extranjera directa (IED) reducen la tasa de emigración de los paises de la región.

Palabras clave: migración internacional; política migratoria; diferencias salariales; capital humano; determinantes.

Clasificación JEL: F22, F02, O15.

\footnotetext{
${ }^{1}$ Ministerio de Hacienda, Santo Domingo, República Dominicana. Correo-e: ybenzan@hacienda.gov.do
}

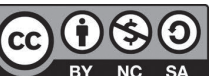




\title{
Determinants of migration in Central America AND The Dominican Republic
}

\author{
Yulisa M. BENZÁn BENZÁN
}

Received: 12/2/2021 A Approved: 01/09/2021

\begin{abstract}
A comprehensive analysis has been conducted on the causes and factors that determine international migration in Belize, Costa Rica, El Salvador, Guatemala, Honduras, Nicaragua, Panama and the Dominican Republic, member countries of the Central American Integration System (SICA). Specifically, a panel data model estimated by effects selected at random is used, covering the period 1990-2015, in which the literature related to economic, geographic, social, commercial, political and cultural factors associated with migration are tested. The results suggest that the perception of higher average incomes, approximated by the income difference between the two countries alone is not sufficient to explain emigration from the region; however, it is the most important structural determinant when social, political and cultural variables are taken into consideration. Furthermore, the study indicates that the population tends to emigrate to countries that guarantee a longer life span, but on the contrary, to societies that are more unequal in economic terms. Insecurity or the perception of risk in the destination country and a greater flow of foreign direct investment (FDI) reduce the rate of emigration from the countries of the region.

- human capital; determinants.

JEL codes: F22, F02, O15.
\end{abstract}




\section{Introducción}

En las últimas décadas el fenómeno de la migración internacional ha mostrado un renovado interés en el oficio de la investigación desde diferentes disciplinas; tanto desde el marco normativo y descriptivo en los estudios tradicionales, como desde la más reciente aplicación de modelos empíricos a fines de explicar sus causas y determinantes, principalmente desde el ámbito económico, social y político (Solimano, 2003).

Sin duda alguna conocer los determinantes de la emigración en la región SICA resulta particularmente importante, debido a que todos los países miembros que la conforman presentan un alto potencial migratorio con tendencia al alza. Esto se evidencia en el comportamiento de su stock de emigrantes en las últimas décadas, distribuidos a nivel mundial, registrando 5,771,940 millones de emigrantes legales ${ }^{1}$ entre 2015 y 2017, equivalente a un incremento de $29.8 \%$ y $13.9 \%$ con respecto a las cifras registradas en los quinquenios de 2005 y 2010, respectivamente (United Nations, 2017) ${ }^{2}$.

El marco analítico del presente artículo deriva de la base de estos enfoques con intención de brindar un análisis general de las causas y determinantes de la emigración en Belice, Costa Rica, El Salvador, Guatemala, Honduras, Nicaragua, Panamá y la República Dominicana, países que conforman el Sistema de la Integración Centroamericana (SICA) ${ }^{3}$; ya que se evalúan variables que afectan el bienestar de los individuos y motivan - o simplemente facilitan - la decisión de abandonar sus países de origen en búsqueda de mejorarlo. Se realiza, específicamente, a partir de un modelo de datos de panel para el período 1990-2015 busca constatar si la emigración proveniente de la región SICA es explicada por factores estructurales de naturaleza económica como las diferencias salariales, las condiciones geográficas y el nivel de empleo, por aspectos de naturaleza

\footnotetext{
${ }^{1}$ El estudio se limita únicamente al estudio de migración legal dado la indisponibilidad de datos oficiales que por naturaleza implica la migración ilegal.

${ }^{2}$ Véase Anexo 1 disponible en la web.

${ }^{3}$ El Sistema de la Integración Centroamericana (SICA) tiene por objetivo fundamental la realización de la integración de Centroamérica, para constituirla como Región de Paz, Libertad, Democracia y Desarrollo (SICA, 2021). Estos países en lo adelante serán denominados en su conjunto como "región SICA".
} 
diversa más relacionados a los individuos como la desigualdad, el nivel de capital humano, la educación, la cultura, y el idioma, o si es posible que se deba a la combinación de estos, tanto en el país de origen como de destino.

Uno de los elementos que diferencia a este trabajo de acuerdo con la literatura consultada en el estudio de este fenómeno es la metodología empírica que se emplea y el conjunto de países que se analizan, que responde, en particular, a la necesidad de abordar con rigurosidad los desafíos y problemáticas actuales.

En última instancia, y no siendo menos importante, está orientado a proveer recomendaciones basadas en evidencia empírica que sirvan para la articulación de políticas, en especial económicas y sociales, que resulten efectivas y coherentes con la realidad de la región. En general, estas políticas suelen utilizarse como mecanismo de ajuste en los países en vías de desarrollo para reducir el flujo de emigrantes, al mismo tiempo que aumentan su grado de participación en el comercio mundial (Alba, 2001).

En la siguiente sección se incluye una síntesis de la revisión de la literatura especializada en la materia orientada a explicar este fenómeno; una descripción de los datos utilizados con las estadísticas descriptivas correspondientes; el marco empírico empleado para el hallazgo de los resultados; la discusión de los resultados; las reflexiones conclusivas del estudio y, posteriormente, algunos comentarios y recomendaciones.

\section{Un acercamiento con la literatura}

A pesar de que la migración internacional es un fenómeno de larga data, es a partir de la última mitad del siglo xix e inicios del siglo xx que surge el proceso de internacionalización económica de la "primera globalización” la cual estuvo caracterizada por una gran movilidad de capitales, que a su vez venía acompañada por la movilidad de la población.

Esta última se vio exacerbada por la fase de consolidación como nación que experimentaban algunos territorios que escaseaban de población principalmente en América y Oceanía- y las primeras etapas de la transición demográfica en otros con altas tasa de crecimiento poblacional, como es el caso de Europa y Estados Unidos. La primera globalización y la movilidad poblacional se complementaron entre sí y ocasionaron los 
cimientos, de lo que más tarde sería una fuerte y diversificada oleada de emigrantes - principalmente hacia Estados Unidos y Canadá, aunque en menor medida a Argentina, Venezuela y Brasil— desde América Latina y el Caribe (ALC) en el período 1960-19904. Partiendo de esto, el estudio de las migraciones se ha realizado desde diversos enfoques y disciplinas, destacando en el área de sociología, historia, las ciencias políticas y económicas, siendo esta última el área de interés para este trabajo.

El estudio de la migración en las ciencias económicas inicia como parte de las ideas clásicas de flujos migratorios con la formulación de la teoría de las diferencias salariales, que plantea que estos actúan como una mano de obra "equilibradora" hasta lograr el balance necesario como consecuencia de las diferencias salariales que existen entre regiones o sectores con un mayor nivel de industrialización y capital (Cantillon, 1755; Smith, 1776; Hicks, 1932 \& 1963; Rosen, 1986; Massey et al. 1993). En particular, en esta disciplina el fenómeno se ha abordado, con el objetivo principal de explicar cuáles son los factores económicos que inciden en los individuos (enfoque micro) o conjunto de individuos (enfoque macro) al momento de emigrar transitoria o de manera permanente de un territorio a otro.

Los modelos detrás de esta teoría, en especial el modelo de Lewis (1954), describen la propensión a migrar a regiones o países que presentan un mayor nivel de desarrollo económico, es decir, que responden a un desequilibrio entre capital y mano de obra entre las zonas rurales y urbanas. Todaro (1969) al considerar como poco realista la teoría de las diferencias salariales que supone pleno empleo introduce la teoría de las diferencias salariales esperadas; que establece una relación positiva entre la emigración y el desempleo en países en vías de desarrollo como resultado de la búsqueda de salarios más altos por parte de su población al emigrar a países o regiones más industrializadas, es decir, que se explica por los diferenciales de ingresos esperados entre zonas geográficas.

Por otra parte, algunos representantes de la teoría neoclásica enfatizan que aspectos relacionados a la oferta de trabajo en el lugar de destino constituyen el principal detonante de los procesos migratorios, mientras

\footnotetext{
${ }^{4}$ Pellegrino, A. (2000) estimó que la tasa de crecimiento promedio de la cantidad de emigrantes de ALC para este período fue de $69.6 \%$.
} 
que otros autores de esta misma corriente plantean que responde más a la fuerza que ejerce la demanda de mano de obra en los sectores productivos e industriales (Piore, 1979). También sostienen que el desequilibrio se genera con la contratación de mano de obra barata no cualificada que se ve regularmente forzada a realizar variadas labores productivas bajo precarias condiciones en términos salariales y acceso a servicios básicos.

Desde los años sesenta la migración se empieza a estudiar tanto asociada a componentes estructurales en los países como también a partir de la integración de otros aspectos más vinculados a los individuos, siendo pioneros Sjaastad (1962) y Borjas (1989) al considerar la decisión de emigrar como una inversión en capital humano motivada por la búsqueda de mejores oportunidades económicas. Subsiguientemente, la migración se ha estudiado desde la disciplina de la sociología con el análisis de características propias del individuo y su entorno familiar; entre estas, se plantea que la decisión de migrar estaría vinculada a la acumulación de capital social adquirido por la cultura y en parte por la educación (Rogers \& Castro, 1982; Massey \& García, 1987; Boyd, 1989)². En otros estudios se han incluido las desigualdades sociales, la cualificación profesional y las características étnicas (Suval \& Hamilton, 1965; Persky \& Kain, 1970; Schwartz, 1973; Weinstein, 1974; Greenwood, 1975; Gordon \& Vickerman 1982).

De igual manera, destaca la aplicación de modelos gravitacionales al campo de estudio de la migración que plantean una relación directamente proporcional entre esta con la población o fuerza, e inversamente proporcional con el cuadrado de la distancia geográfica entre ambos lugares. Es decir, que la preferencia a migrar también puede ser explicada por factores como la distancia, la existencia de bordes comunes y los costes de desplazamiento (Anderson, 1955; Carey, 1858; Molho, 1986; Ravenstein, 1885). Silva (2019) aplica este tipo de modelo en un estudio sobre la migración internacional en Colombia y halla que, ante mejores condiciones socioeconómicas, alto nivel educativo y mayor capital humano en los países receptores, se incrementa la movilidad hacia estos, mientras que

\footnotetext{
${ }_{5}^{5}$ Para ver otros autores destacados en el estudio de la migración dentro de esta disciplina consultar Tajfel (1981), Cernianski (1990), Portes (1997, 2005 \& 2009), Brettell y Hollifield (2000) y Bustamante (2002).
} 
variables como la violencia, la desigualdad y el desempleo resultan poco determinantes en la emigración de la población colombiana.

La integración de la perspectiva política en el estudio de las migraciones es relativamente reciente con respecto a los demás factores, ya que inicia a finales de la década de los 70, mostrando evidencia de que la política actúa más como un factor de expulsión que de atracción en los flujos migratorios (Grimson, 1977; Galvis, 2002; Mayda, 2010, Geddes $\&$ Scholten, 2016). Estos factores se relacionan estrechamente con la legislación migratoria vigente entre el país emisor y el país receptor, al condicionar los flujos migratorios con la supresión de barreras de entrada y/o salida, además de lo relacionado a seguridad nacional e internacional y la política exterior entre países vinculados (Zolberg, 1981; Hollifield, 2000; Santel, 1995; (Roncken, T., Alquizalet, O., Cielo, C., Céspedes, R., $\&$ Serrudo, Y., 2009)) $)^{6}$.

En el área de comercio internacional, la teoría del sistema mundial plantea que hay mayor movilidad poblacional entre países y regiones en la medida en que las relaciones económicas capitalistas traspasen las fronteras de países poco desarrollados con menor arraigo de este sistema económico. Como resultado de los estudios realizados en esta área se ha encontrado evidencia de la existencia de una correlación positiva entre la inmigración y la inversión extranjera directa y una complementariedad o relación de sustitución entre ambas variables (Borjas, 1991; Foad, 2012; Javorcik, 2010).

Del mismo modo, el idioma se ha considerado como una variable relevante en el análisis de la influencia de los aspectos socioculturales sobre los flujos migratorios debido a las restricciones que puede representar para la población migrante al momento de insertarse al mercado laboral y en el acceso a la información, así como en el proceso de adaptación e interacción social con su entorno (Kontuly, Smith \& Heaton, 1995). Igualmente, los nexos coloniales entre países o regiones desvelan la necesidad de considerar la afinidad lingüística, cultural e institucional, siendo esta última particularmente importante en la medida que influye en la flexibilización de las regulaciones migratorias entre los lugares de

\footnotetext{
${ }^{6}$ También se puede consultar a Cernianski (1990), Joppke (1998) e Hinojosa (2009).
} 
origen y destino (Criales, 1994; Neumayer, 2005; Vezzoli \& Flahaux, 2016; Silva, 2019) 7 .

Este trabajo sigue un enfoque mixto con relación al estado de arte en la materia, ya que se analizan tanto las variables de naturaleza económica sugeridas por la teoría de las diferencias salariales y la teoría neoclásica, así como también variables estudiadas en el área de la geografía, sociología, comercio, política y cultura.

\section{Datos y Estadísticas Descriptivas}

Los datos utilizados en las estimaciones corresponden al período 1990-2015 con el propósito de explicar la dinámica de la migración internacional de la población en Belice, Costa Rica, El Salvador, Guatemala, Honduras, Nicaragua, Panamá y la República Dominicana.

Como resultado de la revisión de literatura, y en especial siguiendo a Silva (2019), se procedió a la categorización de un conjunto de variables explicativas y se definió como variable dependiente Número de emigrantes legales por cada 100 mil habitantes del país miembro de la región SICA (i) en cada uno de los 68 países identificados como destinos (j) en el año $t^{8}$. Específicamente, se calcula a partir de la siguiente fórmula:

$$
\text { Número emigrantes }{ }_{i j, t} / \text { Población total }_{i, t} *(100,000)
$$

En esta variable se pondera el acervo de emigrantes del país de origen con respecto a su población total a los fines de capturar mejor la relación entre esta y las demás variables, a través de la minimización de las desviaciones derivadas de la alta variabilidad poblacional que exhiben los países de destino.

Cabe señalar que se efectuaron cortes quinquenales dada la dificultad de construir la serie anual para todas las variables, en particular de la variable dependiente. Es decir, que la información utilizada corresponde

\footnotetext{
${ }^{7}$ Otros estudios más orientados al área de la historia son Marmora (1990), Castles \& Miller (2014), Auj (2008), Maric (2009) y Mazurek, (2009)

${ }^{8}$ Corresponde al quinquenio 2015 e incluye a los propios países de la región SICA, ya que entre estos también hay flujo de migrantes.
} 
al promedio de los últimos cinco años, incluyendo los años de interés 1990, 1995, 2000, 2005, 2010 y para el 2015, se tomó el promedio entre este y los datos disponibles hasta 2017. Esta última parte se hizo con los fines de capturar en términos promedio el comportamiento de las variables entre el período quinquenal y el año de interés.

Asimismo, la selección de la variable dependiente estuvo condicionada a la inexistencia y/o difícil acceso a datos homogéneos de los flujos migratorios anuales para estos países, además de la ventaja que representan en términos de calidad de los registros de la variable dependiente utilizada. A continuación, se presentan la categorización de las variables utilizadas y la descripción general de estas:

Tabla 1. Definición de variables y estadísticas descriptivas

\begin{tabular}{|c|c|c|c|c|c|c|c|c|}
\hline \multirow{2}{*}{ Tipo } & \multirow{2}{*}{ Variable } & \multirow{2}{*}{ Definición } & \multicolumn{2}{|c|}{$\mathbf{N}$} & \multicolumn{2}{|c|}{ Media $(\Sigma)$} & \multirow{2}{*}{ Unidad } & \multirow{2}{*}{ Fuente } \\
\hline & & & País i & País j & País i & País j & & \\
\hline 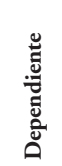 & $\begin{array}{l}\text { Tasa de } \\
\text { emigración }\end{array}$ & $\begin{array}{l}\text { Número de emigrantes del } \\
\text { país de origen por cada } \\
100,000 \text { habitantes en cada } \\
\text { uno de los países destino en } \\
\text { el ańo t. }\end{array}$ & 2035 & - & 225.7 & 1387.18) & Índice & $\begin{array}{l}\text { Naciones } \\
\text { Unidas }\end{array}$ \\
\hline \multirow{2}{*}{ 莺 } & $\begin{array}{l}\text { Diferencias } \\
\text { PIB per } \\
\text { cápita entre } \\
\text { ambos } \\
\text { países }\end{array}$ & $\begin{array}{l}\text { Diferencia entre el PIB per } \\
\text { cápita ajustado por la Paridad } \\
\text { de Poder Adquisitivo (PPA) } \\
\text { en el ańo t. Se usa como } \\
\text { proxy de la diferencia salarial } \\
\text { entre el país de origen y el } \\
\text { país de destino. }\end{array}$ & 2173 & 2173 & \multicolumn{2}{|c|}{$0.6(-0.8)$} & Índice & Banco Mundial \\
\hline & $\begin{array}{l}\text { Tasa de } \\
\text { desempleo }\end{array}$ & $\begin{array}{l}\text { Proporción de la fuerza } \\
\text { laboral en ambos países que } \\
\text { no tiene trabajo pero que } \\
\text { está disponible y en busca de } \\
\text { empleo en el año t. }\end{array}$ & 2191 & 2037 & $\begin{array}{c}5.6 \\
(-2.2)\end{array}$ & $8(-4.5)$ & $\%$ & Banco Mundial \\
\hline \multirow{2}{*}{ 焉 } & $\begin{array}{l}\text { Distancia } \\
\text { física }\end{array}$ & $\begin{array}{l}\text { Distancia entre el país de } \\
\text { origen y el país de destino } \\
\text { calculada con la fórmula del } \\
\text { gran círculo. }\end{array}$ & 2035 & 2035 & 6019.6 & $(-3999.2)$ & $\mathrm{km} 2$ & $\begin{array}{l}\text { Centre d'Études } \\
\text { Prospectives et } \\
\text { d'Informations } \\
\text { Internationales } \\
\quad \text { (CPII) }\end{array}$ \\
\hline & $\begin{array}{l}\text { Bordes } \\
\text { geográficos }\end{array}$ & $\begin{array}{l}\text { Indica si el país de origen } \\
\text { comparte bordes geográficos } \\
\text { con el país de destino. Toma } \\
\text { valor de } 1 \text { en caso afirmativo, } \\
\text { y valor } 0 \text { en caso contrario. }\end{array}$ & 2035 & 2035 & & - & Binaria & CPII \\
\hline
\end{tabular}




\begin{tabular}{|c|c|c|c|c|c|c|c|c|}
\hline \multirow{2}{*}{ Tipo } & \multirow{2}{*}{ Variable } & \multirow{2}{*}{ Definición } & \multicolumn{2}{|c|}{$\mathbf{N}$} & \multicolumn{2}{|c|}{ Media $(\Sigma)$} & \multirow{2}{*}{ Unidad } & \multirow{2}{*}{ Fuente } \\
\hline & & & País i & País j & País i & País j & & \\
\hline \multirow{4}{*}{.ँّ } & $\begin{array}{l}\text { Esperanza } \\
\text { de vida }\end{array}$ & $\begin{array}{l}\text { Indica la cantidad de ańos } \\
\text { que viviría un recién nacido } \\
\text { pata ambos países en el año t. }\end{array}$ & 2035 & 2035 & $\begin{array}{l}72.2 \\
(-3.8)\end{array}$ & $\begin{array}{l}75.6 \\
(-5.0)\end{array}$ & Años & Banco Mundial \\
\hline & $\begin{array}{l}\text { Años de } \\
\text { escolaridad } \\
\text { promedio }\end{array}$ & $\begin{array}{l}\text { Años promedio de estudio } \\
\text { de la población para ambos } \\
\text { países en el ańo t. }\end{array}$ & 2035 & 1936 & $\begin{array}{c}6.4 \\
(-1.9)\end{array}$ & $\begin{array}{c}9.4 \\
(-2.6)\end{array}$ & Años & $\begin{array}{l}\text { Unesco, Barro- } \\
\text { Lee Education } \\
\text { DataBase }\end{array}$ \\
\hline & $\begin{array}{l}\text { Índice de } \\
\text { Gini }\end{array}$ & $\begin{array}{l}\text { Mide el grado la desviación } \\
\text { de la distribución del ingreso } \\
\text { entre individuos u hogares } \\
\text { dentro de ambos países } \\
\text { con respecto a distribución } \\
\text { perfectamente en el año t. }\end{array}$ & 2035 & 1738 & $\begin{array}{c}34 \\
(17.6)\end{array}$ & $\begin{array}{c}24.5 \\
(-14.4)\end{array}$ & Índice & Banco Mundial \\
\hline & $\begin{array}{l}\text { Tasa de } \\
\text { homicidio }\end{array}$ & $\begin{array}{l}\text { Mide la relación entre la } \\
\text { cantidad de estos sucesos } \\
\text { mortales por cada } 100,000 \\
\text { habitantes para ambos países } \\
\text { en el ańo t. }\end{array}$ & 2035 & 1901 & $\begin{array}{c}24.3 \\
(-21.8)\end{array}$ & $\begin{array}{c}10.5 \\
(-15.9)\end{array}$ & $\%$ & Banco Mundial \\
\hline 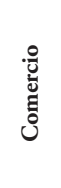 & $\begin{array}{l}\text { Inversión } \\
\text { extranjera } \\
\text { directa } \\
\text { (IED) }\end{array}$ & $\begin{array}{l}\text { Flujo de entrada neta de } \\
\text { inversiones para obtener un } \\
\text { control de gestión duradero } \\
\text { de una empresa que funciona } \\
\text { en el país de origen en el ańo } \\
\text { t como \% del PIB }\end{array}$ & 2035 & - & $\begin{array}{c}4 \\
(-2.5)\end{array}$ & - & $\%$ & Banco Mundial \\
\hline \multirow{2}{*}{ 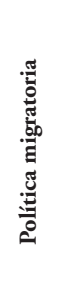 } & $\begin{array}{l}\text { Conflicto } \\
\text { político } \\
\text { interno }\end{array}$ & $\begin{array}{l}\text { Toma valor de } 1 \text { si en el año } \\
\text { t hubo un conflicto interno o } \\
\text { guerra intraestatales en el país } \\
\text { de destino y valor } 0 \text { en caso } \\
\text { contrario. }\end{array}$ & & 035 & & - & Binaria & $\begin{array}{l}\text { Peace Research } \\
\text { Institute Oslo } \\
\text { (PRIO) }\end{array}$ \\
\hline & Visado & $\begin{array}{l}\text { Toma valor de } 1 \text { si el país } \\
\text { clave requiere visa para la } \\
\text { entrada al país de destino. }\end{array}$ & & 035 & & - & & $\begin{array}{l}\text { Visa List } \\
\text { website }\end{array}$ \\
\hline \multirow{2}{*}{ 㞼 } & $\begin{array}{l}\text { Relación } \\
\text { colonial }\end{array}$ & $\begin{array}{l}\text { Toma valor de } 1 \mathrm{si} \\
\text { ambos países comparten } \\
\text { antecedentes históricos de } \\
\text { relación colonial origen y } \\
\text { valor de } 0 \text { en caso contrario. }\end{array}$ & & 035 & & - & Binaria & CPII \\
\hline & $\begin{array}{l}\text { Proximidad } \\
\text { lingüística }\end{array}$ & $\begin{array}{l}\text { Toma valor de } 1 \text { si el lenguaje } \\
\text { de ambos países comparte } \\
\text { raíces - p. ej., si ambas son } \\
\text { leguas romances - y toma el } \\
\text { valor } 0 \text { en caso contrario. }\end{array}$ & & 035 & & - & Binaria & CPII \\
\hline
\end{tabular}




\section{Marco empírico}

\section{Especificación del modelo}

Se plantea el desarrollo de un modelo agregado que se específica tomando en consideración la base empírica de los trabajos y enfoques que han marcado las pautas en el desarrollo de este tipo de modelos en el estudio de la migración (Todaro, 1976; García Ferrer, 1980; Burridge \& Gordon, 1981) $)^{9}$.Concretamente, el modelo básico a estimar tiene la siguiente forma funcional:

$$
\operatorname{LnEMIG}_{i, t, t}=\beta_{0}+\beta_{1} P_{i i_{i j, t}}+\beta_{2} \operatorname{LnDIST}_{i, t}+\beta_{3} \operatorname{DESEMP}_{i, t}+\beta_{4} \operatorname{DESEMP}_{j, t}+\beta_{n} V E_{i, t}+\varepsilon_{i, \mathrm{t}}
$$

Donde $\mathrm{EMIG}_{\mathrm{i}, \mathrm{t}}$ corresponde al número emigrantes por cada $100 \mathrm{mil}$ habitantes del país i en el país $\mathrm{j}$; PIB $_{\mathrm{i}, \mathrm{t}}$ es la diferencia entre del PIB per cápita (PPA) del país i y el PIB per cápita (PPA) del país $\mathrm{j}$; DIST $\mathrm{Di}_{\mathrm{i}, \mathrm{t}}$ es la distancia física entre ambos países; DESEMP ${ }_{\mathrm{i}, \mathrm{t}}$ y DESEMP ${ }_{\mathrm{j}, \mathrm{i}}$ representan las tasas de desempleo del país i y j, respectivamente; $\mathrm{VE}_{\mathrm{i}, \mathrm{t}}$ representa un vector de las demás variables presentadas en la tabla 1 a ser incluidas en otras especificaciones del modelo básico a estimar inicialmente.

Esto último, debido a que la inclusión de demasiadas variables explicativas puede provocar multicolinealidad y reducir la capacidad explicativa del modelo (Anderson, 1955). Se plantean varias especificaciones en aras de constatar las otras hipótesis encontradas en la revisión de literatura con la inclusión escalonada de las demás variables previamente categorizadas en el vector $\mathrm{VE}_{\mathrm{ij}, \mathrm{t}}$.

En general, la especificación básica del modelo busca constatar la hipótesis sugerida en la teoría de las diferencias salariales aproximada por la variable explicativa PIB $_{\mathrm{ij}, \mathrm{t}}$, en los modelos gravitacionales de migración con DIST $\mathrm{T}_{\mathrm{i}, \mathrm{t}} \mathrm{y}$ en la teoría de las diferencias salariales esperadas con la inclusión de las variables DESEMP ${ }_{\mathrm{i}, \mathrm{t}}$ y DESEMP ${ }_{\mathrm{j}, \mathrm{t}}$.

Finalmente, el uso de la forma funcional $\log$ - $\log$ para el coeficiente $\beta 2$, con relación a la variable dependiente responde a la necesidad de eliminar

\footnotetext{
${ }^{9} \mathrm{La}$ forma funcional, las variables incluidas y las omitidas se suelen justificar en la literatura con base en razonamientos microeconómicos más o menos ad hoc.
} 
el efecto de la unidad de medida distinta de la distancia física $\left(\mathrm{km}^{2}\right)$ sobre la tasa de emigrantes. Específicamente, $\beta 2$ mide la elasticidad de la tasa de emigrantes en el país de origen por cada 100,000 habitantes, con respecto a la distancia física entre este y el país de destino.

\section{Estrategia de Estimación}

Primero, se verificó que la metodología de datos de panel era adecuada debido a que el estimador por Mínimos Cuadrados Ordinarios (MCO) estima parámetros inconsistentes e ineficientes al ignorar la existencia de los efectos individuales y temporales sugeridos por la prueba de Hausman; que compara los $\beta$ obtenidos por medio del estimador estático (efectos fijos y efectos aleatorios) con el estimador MCO, identificando si las diferencias entre ellos son o no significativas. Igualmente, dada la naturaleza y estructura de los datos resulta conveniente este tipo de análisis al presentar ventajas frente a otras cuando se trabajan paneles incompletos (Roodman, 2008; Labra \& Torrecillas, 2014) ${ }^{10}$.

La presencia de heterogeneidad no observable hace necesario utilizar técnicas de datos de panel que sean capaces de capturar de forma adecuada la relación entre variables debido a que el no reconocimiento de esta puede provocar alteraciones en los interceptos a través del tiempo o entre unidades de corte transversal, es decir, un sesgo sobre los estimadores de los parámetros al asumir que las observaciones y características de los países son homogéneas. En general, estos cambios se aproximan con la inclusión de variables binarias o a partir del componente aleatorio del modelo en sí, el modelo de efectos fijos y el modelo de efectos aleatorios, respectivamente (Baronio \& Vianco, 2014).

Una vez descartados los resultados por $\mathrm{MCO}$, se procedió a determinar si los coeficientes del modelo estático del estimador por efectos fijos (consistentes) y el estimador por efecto aleatorios (eficientes) presentan diferencias sistemáticas significativas ${ }^{11}$. La prueba de Hausman concluyó

\footnotetext{
${ }^{10}$ Esta característica se constata en que el número de años o variables observados para cada país no es el mismo, además de que hay que considerar que se tiene una muestra relativamente grande con respecto al número de períodos quinquenales.

${ }^{11}$ Para más detalles véase Aguilera (2020).
} 
la selección del estimador por efectos fijos para las especificaciones (1), (2) y (3), mientras que el estimador por efectos aleatorios para las especificaciones (4), (5) y (6), por ser los coeficientes de estas últimas considerados ortogonalmente iguales a los del estimador por efectos fijos ${ }^{12}$. Sin embargo, las especificaciones sugeridas por el modelo de efectos fijos presentan una fuerte limitante a fines de evaluar las causas y determinantes de la migración internacional bajo un enfoque integral debido a que elimina información del modelo al imposibilitar la estimación de los parámetros de las variables que permanecen constantes en el tiempo tal es el caso de las variables binarias-, siendo esta última una característica de algunas de las variables utilizadas y sugeridas en la literatura para la constatación de ciertas hipótesis.

Por consiguiente, el modelo de efectos aleatorios considera que estos cambios o efectos individuales no son independientes entre sí, y, por ende, que el efecto de los regresores sobre la variable explicada y las características propias de cada unidad en el sistema de datos son diferentes, permitiendo distinguir el efecto de cada individuo u observación en el panel de datos a través del término . Específicamente, este modelo se plantea algebraicamente de la siguiente forma:

$$
\begin{gathered}
Y_{i, t}=\left(a+u_{\mathrm{i}}\right)+b_{1} Z_{1 i, t}+\cdots b_{k} Z_{k i, t}+w_{i, t} \operatorname{con} i=1, \ldots, n, t=\cdots, T \\
Y_{i, t}=a+Z_{1 i, t}+\cdots b_{k} Z_{k i, t}+U_{i, t} \operatorname{con} i=1, \ldots, n, t=\cdots, T
\end{gathered}
$$

Como resultado de la agrupación de los componentes estocásticos del modelo en [4] se obtiene la relación $U_{i, t}=u_{i}+v_{t}+w_{i, t}$ donde $u_{i}$ y $v_{t}$ capturan los efectos no observables y no cuantificables que varían entre unidades (corte transversal) y en el tiempo (series de tiempo), respectivamente, mientras que $w_{i, t}$ es un término de error aleatorio que combina a ambas. En el modelo utilizado se considera que existen choques temporales específicos con el uso del modelo de componente de error "two ways" o en doble sentido, $v_{t} \neq 0$ sobre la premisa de que estos no se cuantifican en la regresión (Mayorga \& Muñoz, 2000).

Un aspecto que hay que tomar en cuenta con razón a las variables binaria explicativas utilizadas en este tipo de modelos con forma funcional

${ }^{12}$ Véase Anexo 2 y Anexo 3 en la web. 
Log-Lin es que no pueden ser interpretadas de forma habitual $\left(\beta^{*} 100\right)$ debido a que no es posible derivar con respecto al parámetro, por ser una variable dicotómica (Alonso \& Muñoz, 2014). La aproximación de la interpretación de las variables binarias en este estudio responde a la siguiente fórmula:

$$
(Y i \mid D i=1) /(Y i \mid D i=0)
$$

Seguidamente, se consideran más adecuadas las estimaciones del modelo por efectos aleatorios ${ }^{13}$ dado que sus coeficientes tampoco presentan desviaciones cuantiosas, con respecto a las estimaciones por efectos fijos. No obstante, hay que advertir que, aunque la literatura sugiere que el estimador por efectos aleatorios es más exacto en el cálculo del valor del parámetro este también es más propenso a sobrestimarlo (Granados, 2011); además, hay que tener en cuenta que los datos faltantes en algunas variables podrían comportarse como variables omitidas y generar cierto grado de inconsistencia.

Mientras, que dados los resultados de algunas pruebas de validación aplicadas al modelo original estimado por efectos aleatorios, este fue corregido (Tabla 2) por heterocedasticidad y correlación serial utilizando la matriz de covarianza robusta de los parámetros desarrollada por Arellano (1987) ante los riesgos de pérdida de eficiencia en los parámetros que expone Greene (2003). En esencia, corrige por heterocedasticidad y correlación serial a partir de una estructura completamente general; siendo los errores estándar de esta matriz denominados como errores estándar robustos a heterocedasticidad, permitiendo realizar inferencia sin necesidad de especificar el tipo de heterocedasticidad.

Finalmente, es preciso reiterar que los resultados están sujetos a la disponibilidad y calidad de los datos utilizados y a las limitaciones que presenta el uso de este tipo de técnicas econométricas en términos explicativos sobre este tipo de fenómeno. Asimismo, los resultados de las estimaciones referidas en esta sección pueden ser replicados usando las bases de datos y códigos colocados en la versión web del artículo.

${ }^{13}$ Ad Hoc. 


\section{Resultados y discusión}

Tabla 2. modelo estimado por efectos aleatorios ajustado

\begin{tabular}{|c|c|c|c|c|c|c|}
\hline \multirow{3}{*}{ Variables } & \multicolumn{6}{|c|}{ Ln (Número de emigrantes i en j/Población total i)*100,000 } \\
\hline & Esp. 1 & Esp. 2 & Esp.3 & Esp.4 & Esp. 5 & Esp.6 \\
\hline & (1) & (2) & (3) & (4) & (5) & (6) \\
\hline \multirow{2}{*}{$\begin{array}{l}\text { Diferencias } \\
\text { PIB per cápita } \\
\text { entre it y jt }\end{array}$} & -0.042 & $-0.174^{* * *}$ & $-0.279^{* * *}$ & $-0.274^{* * *}$ & $-0.267^{* * *}$ & $-0.287^{* * *}$ \\
\hline & $(0.047)$ & $(0.060)$ & $(0.064)$ & $(0.065)$ & $(0.065)$ & $(0.070)$ \\
\hline \multirow{2}{*}{$\begin{array}{c}\text { Ln Distancia } \\
\text { Física entre } \\
\text { it y jt }\end{array}$} & $-1.215^{* * *}$ & $-1.369^{* * *}$ & $-1.576^{* * *}$ & $-1.597^{* * *}$ & $-1.594^{* * *}$ & $-1.611^{* * *}$ \\
\hline & $(0.088)$ & $(0.094)$ & $(0.093)$ & $(0.089)$ & $(0.089)$ & $(0.185)$ \\
\hline \multirow{2}{*}{$\begin{array}{c}\text { Tasa de } \\
\text { desempleo it }\end{array}$} & 0.01 & $0.028^{*}$ & 0.012 & 0.01 & 0.013 & 0.013 \\
\hline & $(0.016)$ & $(0.016)$ & $(0.017)$ & $(0.017)$ & $(0.017)$ & $(0.017)$ \\
\hline \multirow{2}{*}{$\begin{array}{c}\text { Tasa de } \\
\text { desempleo jt }\end{array}$} & $-0.015^{* *}$ & -0.009 & $-0.017^{* * *}$ & $-0.018^{* * *}$ & $-0.018^{* * *}$ & $-0.020^{* * *}$ \\
\hline & $(0.007)$ & $(0.007)$ & $(0.006)$ & $(0.007)$ & $(0.006)$ & $(0.006)$ \\
\hline \multirow{2}{*}{$\begin{array}{c}\text { Esperanza de } \\
\text { vida it }\end{array}$} & & 0.011 & $-0.030^{*}$ & -0.026 & -0.024 & -0.024 \\
\hline & & $(0.015)$ & $(0.017)$ & $(0.017)$ & $(0.017)$ & $(0.017)$ \\
\hline \multirow{2}{*}{$\begin{array}{l}\text { Esperanza de } \\
\text { vida jt }\end{array}$} & & 0.023 & $0.033^{* *}$ & $0.036^{* *}$ & $0.037^{* * *}$ & $0.035^{* *}$ \\
\hline & & $(0.015)$ & $(0.014)$ & $(0.014)$ & $(0.014)$ & $(0.014)$ \\
\hline \multirow{2}{*}{$\begin{array}{c}\text { Años de } \\
\text { escolarización } \\
\text { prom. it }\end{array}$} & & 0.006 & $0.078^{* * *}$ & $0.067^{* * *}$ & $0.062^{* *}$ & $0.064^{* * *}$ \\
\hline & & $(0.023)$ & $(0.024)$ & $(0.025)$ & $(0.024)$ & $(0.024)$ \\
\hline \multirow{2}{*}{$\begin{array}{c}\text { Años de } \\
\text { escolarización } \\
\text { prom. jt }\end{array}$} & & $0.055^{* * *}$ & $0.062^{* * *}$ & $0.055^{* * *}$ & $0.057^{* * *}$ & $0.059^{* * *}$ \\
\hline & & (0.019) & (0.019) & (0.019) & (0.019) & (0.019) \\
\hline \multirow{2}{*}{$\begin{array}{c}\text { Índice de } \\
\text { Gini it }\end{array}$} & & & -0.001 & -0.001 & 0 & -0.001 \\
\hline & & & $(0.002)$ & $(0.002)$ & $(0.002)$ & $(0.002)$ \\
\hline \multirow{2}{*}{$\begin{array}{c}\text { Índice de } \\
\text { Gini jt }\end{array}$} & & & $0.006^{* * *}$ & $0.006^{* * *}$ & $0.007^{* * *}$ & $0.007^{* * *}$ \\
\hline & & & $(0.002)$ & $(0.002)$ & $(0.002)$ & $(0.002)$ \\
\hline \multirow{2}{*}{$\begin{array}{c}\text { Tasa de } \\
\text { homicidio it }\end{array}$} & & & -0.002 & -0.002 & -0.001 & -0.001 \\
\hline & & & $(0.001)$ & $(0.001)$ & $(0.001)$ & $(0.001)$ \\
\hline \multirow{2}{*}{$\begin{array}{c}\text { Tasa de } \\
\text { homicidio jt }\end{array}$} & & & $-0.008^{* *}$ & $-0.008^{* *}$ & $-0.007^{* *}$ & $-0.007^{* *}$ \\
\hline & & & $(0.003)$ & $(0.003)$ & $(0.003)$ & $(0.003)$ \\
\hline \multirow{2}{*}{$\begin{array}{l}\text { Conflicto } \\
\text { político } \\
\text { interno jt } \\
\text { (dummy) }\end{array}$} & & & & 0.058 & 0.052 & 0.053 \\
\hline & & & & $(0.056)$ & $(0.055)$ & $(0.055)$ \\
\hline
\end{tabular}




\begin{tabular}{|c|c|c|c|c|c|c|}
\hline \multirow{3}{*}{ Variables } & \multicolumn{6}{|c|}{ Ln (Número de emigrantes i en j/Población total i)*100,000 } \\
\hline & Esp. 1 & Esp.2 & Esp.3 & Esp.4 & Esp.5 & Esp.6 \\
\hline & (1) & (2) & (3) & (4) & (5) & (6) \\
\hline \multirow{2}{*}{$\begin{array}{l}\text { Visado para } \\
\text { entrada en jt } \\
\text { (dummy) }\end{array}$} & & & & $1.263^{* * *}$ & $1.267^{* * *}$ & $1.227^{* * *}$ \\
\hline & & & & $(0.287)$ & $(0.288)$ & $(0.283)$ \\
\hline \multirow{2}{*}{$\begin{array}{l}\text { Inversión } \\
\text { extranjera } \\
\text { directa it }\end{array}$} & & & & & $-0.016^{*}$ & $-0.016^{*}$ \\
\hline & & & & & $(0.009)$ & $(0.009)$ \\
\hline \multirow{2}{*}{$\begin{array}{c}\text { Relación } \\
\text { colonial } \\
\text { entre it y jt } \\
\text { (dummy) }\end{array}$} & & & & & & $3.053^{* * *}$ \\
\hline & & & & & & $(0.614)$ \\
\hline \multirow{2}{*}{$\begin{array}{c}\text { Proximidad } \\
\text { lingüística } \\
\text { entre it y jt } \\
\text { (dummy) }\end{array}$} & & & & & & -0.147 \\
\hline & & & & & & $(0.378)$ \\
\hline \multirow{2}{*}{$\begin{array}{c}\text { Bordes } \\
\text { geográficos } \\
\text { compartidos } \\
\text { entre it y jt } \\
\text { (dummy) }\end{array}$} & & & & & & 0.423 \\
\hline & & & & & & $(0.413)$ \\
\hline \multirow{2}{*}{ Constante } & $11.656^{* * *}$ & $9.839^{* * *}$ & $13.647^{* * *}$ & $13.039^{* * *}$ & $12.782^{* * *}$ & $13.036^{* * *}$ \\
\hline & $(0.737)$ & $(1.260)$ & $(1.360)$ & (1.348) & (1.341) & (2.019) \\
\hline
\end{tabular}

Nota: los niveles de significación estadística presentados son ${ }^{* * *}$ significativo al $1 \%$; ** significativo al $5 \%$; $\mathrm{y}^{*}$ significativo al $10 \%$.

La especificación (1) del modelo estimado por efectos aleatorios ajustado sugiere que el aumento de la renta promedio, medido a través de las diferencias entre PIB per cápita, en los países de origen no resulta suficiente para retener a sus habitantes y que estos renuncien a las posibilidades que tendrían de percibir ingresos más altos al emigrar.

Por otra parte, se corrobora lo planteado en los modelos gravitacionales de migración debido a que la elasticidad de la distancia física existente entre países mantiene una relación robusta y negativa con respecto al número de emigrantes, es decir, que reduce los flujos migratorios de la región SICA. No obstante, hay que considerar que esta variable no captura en sí el impacto que ha tenido el abaratamiento y diversificación 
de los medios de transporte sobre la dinámica de migración internacional, especialmente tras el uso generalizado de la maquinaria de vapor en la navegación marítima y a la extensión del ferrocarril desde finales del siglo XIX.

Según se observa en (2) tras la inclusión de las variables del tipo social, se produce un efecto multiplicador importante sobre la distancia y la tasa de desempleo, pero en especial sobre las diferencias salariales, que ahora sí aparece como un determinante importante según sugiere la teoría de las diferencias salariales. No obstante, considerando que la tasa de desempleo solo es robusta únicamente en esta especificación, se sugiere que los emigrantes de la región no aparentan considerar el nivel desempleo en su país de origen al momento de migrar, pero si la probabilidad de encontrar empleo en el país destino según planteó Todaro (1969). Específicamente, los individuos evalúan el nivel de empleabilidad o demanda de trabajo en el lugar de destino. Estos resultados son coherentes con las grandes transformaciones sociales a nivel mundial que surgieron a partir de los años 70, en especial el inicio de la globalización económica, que trae consigo mayor movilidad y flexibilidad de todos los factores productivos, especialmente lo que podría denominarse la "industrialización" del factor trabajo a través de la exportación de mano de obra.

Con respecto a la influencia de la escolaridad promedio del país de origen se constata una relación positiva con la tasa de emigración, esto puede deberse a que la población con mayor capital humano considera la probabilidad de obtener un mayor retorno de este en los países de destino, estando más tentada a emigrar. Asimismo, a medida que aumenta el grado de escolarización de los países receptores estos se hacen más atractivos a los flujos migratorios provenientes de la región SICA, lo que difiere del efecto negativo que pudiera intuirse si se considera que estos generalmente presentan mayor Índice de Capital Humano (ICH) y, por ende, su población inmigrante debería tener mayor dificultad para hallar empleo frente a sus pares ya que representan una "competencia".

De forma análoga, en (3), con la adición del índice de Gini y la tasa de homicidio para ambos países, se evidencia que en promedio la población emigrante de la región considera únicamente la desigualdad en la distribución del ingreso y la tasa de homicidio del país receptor como un factor rele- 
vante al momento de emigrar. Específicamente, estos se trasladan a destinos que presentan altos niveles de desigualdad mientras que son adversos a la inseguridad que sugieren las altas tasas de homicidio.

En resumen, los resultados en (2) y (3) sugieren que la población migrante de la región tiende a emigrar a países que garanticen una vida más longeva y saludable, no obstante, también son más proclives a emigrar a sociedades más desiguales en términos económicos. En referencia a este último aspecto, se constata que la interacción entre desigualdad y globalización son factores que acrecientan la emigración esperada en la medida que esta última reduce los costes asociados al desplazamiento, este fenómeno suele darse en período de acentuada y asimétrica globalización (Alonso, 2011).

En (4) se verifica que la existencia de conflictos internos o intraestatales en los países de destino no resulta relevante en la migración de la población proveniente de la región SICA, teniendo, además, un efecto opuesto al sugerido en la literatura al considerarse como factor expulsor en la intensidad y dirección de las migraciones.

Asimismo, con la inclusión de la variable requerimiento de visado se evalúa el efecto de las políticas migratorias permisibles o prohibitivas para la salida de personas a través de la exigencia de visado para la salida del país de destino. Consiguientemente, a pesar de que esta presenta una relación positiva y robusta con respecto al número de emigrantes de los países miembros del SICA, esto no implica que se produzcan mayores desplazamientos desde la región hacia los países que tienen vigente estas regulaciones, sino que también puede sugerir la redirección de los flujos migratorios y no siempre un incremento de estos (Weil, 2002).

Otra posible explicación es que los países de destino que no presentan este tipo de regulaciones podrían no resultar atractivos a la población emigrante de la región SICA, por la ausencia de las condiciones económicas que generalmente buscan al trasladarse, o ante la probable similitud de los países que no tienen el requisito de visado con su país de origen. Asimismo, puede que este resultado contra-intuitivo sea consecuencia de que los datos utilizados corresponden solo a la migración internacional legal, es decir, que el "aumento" de las migraciones hacia países receptores con políticas migratorias más rígidas responda a que solo se estén usando 
datos de emigrantes legales y, por ende, se omite una parte importante de los flujos que puede incidir sobre este resultado.

Por otra parte, contrario a lo que plantea la teoría del sistema de comercio mundial, que a medida que aumente el nivel de comercio o la movilidad de capital entre países también se incrementará la movilidad migratoria, en los países de la región, a medida que aumentan los flujos de inversión extranjera directa se reduce la tasa de emigración (5). Si se parte del hecho de que estos países están en vías de desarrollo, estas pueden ser buenas noticias dado el alto potencial migratorio que presentan a consecuencia del impacto de la globalización con la apertura de las fronteras a nivel mundial.

No obstante, se debe reconocer que este hecho puede considerarse como una desventaja en la medida que los países presentan una alta dependencia de las remesas o migración laboral de los trabajadores que deciden trasladarse a otros países motivados por las condiciones económicas que presentan generalmente los países en vías de desarrollo y en búsqueda de mejor calidad de vida. Sin embargo, al considerar que las remesas solo representan apenas un $15 \%$ de los ingresos del migrante destinado en su mayoría a consumo básico—y el $85 \%$ restante se queda en el país de destino, es indiscutible la importancia económica que tiene para los países de origen retener a su población siempre que se garanticen las condiciones necesarias para su desarrollo y participación en el aparato productivo nacional (Noticias ONU, 2018).

Por su parte, en $(6)^{14}$ se sugiere que la proximidad lingüística y la existencia de bordes geográficos compartidos no resultan un factor condicionante para los emigrantes de los países de origen, pero sí incide positivamente la existencia de antecedentes coloniales compartidos entre ambas partes. Esto puede estar relacionado o ser producto del fuerte efecto disuasorio que han experimentado en las últimas décadas los límites nacionales, la distancia, la cultura y el propio idioma.

\footnotetext{
${ }^{14}$ En el Anexo 4 disponible en la web del artículo se presenta de forma resumida los efectos causales encontrados en esta última especificación de todas las variables explicativas sobre la variable dependiente.
} 


\section{Observaciones finales}

Los resultados del análisis de los determinantes de la migración internacional en los países miembros de la región SICA durante el período 1990-2015 concluyen en que las diferencias salariales entre ambos países, aproximadas por las diferencias entre PIB per cápita, por sí solas no resultan suficientes para explicar la emigración de la población de los países de Centroamérica y República Dominicana. No obstante, cuando se conjuga con variables del tipo social, político y cultural estas constituyen el determinante estructural más importante de la emigración de región.

Igualmente, se corroboró la hipótesis planteada en los modelos gravitacionales de migración, aunque puede que el abaratamiento y diversificación que han tenido los medios de transporte en el último siglo incidan en que la distancia física existente entre los países de la región y los países de destino no constituya una de las causas más determinantes de la emigración en la región.

La dinámica de migración en la región está también influenciada por factores de naturaleza social, pudiendo sugerirse que los individuos con mayor capital humano recurren a la emigración en busca de un mayor retorno de este y mejores oportunidades, según lo sugerido en la literatura. En este sentido, el nivel de escolaridad promedio y la esperanza de vida aparecen como el determinante social de la emigración de la región más importante, sin embargo, también la población en estos países es propensa a emigrar a sociedades más desiguales.

Por otra parte, los conflictos armados internos en los países de destino, la proximidad lingüística y la existencia de bordes geográficos compartidos no inciden sobre las corrientes migratorias de la región, sin embargo, los resultados obtenidos a partir de la tasa de homicidio sugieren que la inseguridad ciudadana actúa como un factor expulsión para las corrientes migratorias de los países de la región SICA.

Un hallazgo interesante es que el número de emigrantes presenta una relación positiva con el establecimiento de regulaciones migratorias en los países de destino, específicamente el requerimiento de visado para la entrada, contrario a lo planteado en la literatura al considerar estas restricciones como un factor expulsión u obstáculo que determinan la movilidad de las personas. En lo que concierne a la teoría del sistema mundial 
del comercio, se sugiere que para el caso de la región SICA no se cumple y, en consecuencia, los países que tienen una menor movilidad de capitales registran un mayor número de emigrantes.

El antecedente de relación colonial entre los países emisores y receptores presenta una incidencia positiva en las migraciones en la región. En virtud de esto, se pudiera inferir que la existencia de rasgos culturales y las facilidades en materia de apertura migratoria que puedan establecerse de forma bilateral entre ambos países, como consecuencia de la relación colonial, actúan como determinantes culturales.

Por último, conscientes de que el proceso de integración económica genera en sí incidencia sobre los flujos migratorios internacionales y en consecuencia no supone precisamente un fenómeno que debe detenerse si se sigue a Castles S. (2010), se plantean algunas observaciones y recomendaciones generales (Cuadro 3) orientadas a disipar las causas y determinantes de naturaleza socioeconómica que actúan como un factor expulsión en los países de la región SICA, —y por ende responde a un desplazamiento forzado en busca de nuevas oportunidades - con el objetivo de revertir esta dinámica a lo que se ha denominado ampliamente como el derecho a no emigrar en el largo plazo.

\section{Comentarios y recomendaciones}

En virtud de que las diferencias salariales constituyen el determinante estructural que más impulsa la migración desde países de la región —en su mayoría dentro del umbral ingreso bajo e ingreso mediano bajo ${ }^{15}$ hacia países de destino con ingresos altos, una gran parte de la literatura sugiere que las políticas económicas deben estar dirigidas a lograr un crecimiento económico sostenido como principal instrumento a la hora de contrarrestar los flujos migratorios. No obstante, una característica que generalmente suelen presentar las economías en vías de desarrollo o

\footnotetext{
15 Según la clasificación del Banco Mundial para el período 2018-2019 basada en el método del Atlas el ingreso nacional bruto (INB) per cápita de El Salvador, Honduras y Nicaragua se encuentra en el grupo de países de ingresos bajo; Belice, Costa Rica, Ecuador y República Dominicana dentro del grupo de ingreso mediano bajos; y únicamente Panamá dentro del umbral de ingresos altos (The World Bank, 2018).
} 
emergentes es un crecimiento acelerado del PIB - como es el caso de la mayoría de los países de la región-, sin embargo, esto no se traduce necesariamente en que estos estén alcanzando un mayor nivel de desarrollo o bienestar en su población.

En ese sentido, se requiere que los países de la región coordinen sus esfuerzos y políticas a la consecución de un crecimiento sostenible, pero que también sea equitativo e inclusivo, que se traduzcan en la mejora de la condición de vida de su población a través del acceso oportuno a servicios de mayor calidad, avances en el nivel de salud, mejor infraestructura habitacional, así como un nivel educativo de calidad y competitivo (Aragonés Castańer \& Salgado Nieto, 2011). Con respecto a este particular, también el crecimiento de la Formación Bruta de Capital Fijo (FBK) y la reducción del desempleo han demostrado ser eficientes en la disminución del volumen internacional de emigrantes en Bahamas, Barbados, Belice y Guyana durante el período 1990-2013 (Navarro Chávez, Ayvar Campos, \& Zamora Torres, 2016).

Por otra parte, el propio sistema capitalista posibilita la persistencia de las graves desigualdades que exhiben generalmente los países de origen; esto provoca que los desplazamientos se reduzcan o retarden de acuerdo con la necesidad de buscar mejores oportunidades económicas y calidad de vida, es decir, obtener el mayor retorno posible de los factores de producción con los que cuenta la población emigrante. Tal como plantea la teoría neoclásica, debido a las diferencias en términos de salario real que existen entre países, la oferta o demanda de trabajo tenderá siempre hacia el desequilibrio, por lo que las diferencias salariales responden más adecuadamente a políticas orientadas a generar empleos bien remunerados y suficientes, así como a la reducción de la desigualdad en el ingreso de los países con alto potencial migratorio. Específicamente, se requiere la creación de empleos formales y de calidad en la región con el objetivo de lograr la redistribución del ingreso en beneficio de la clase trabajadora más desfavorecida, esperando que resulte en la reducción de sus niveles de pobreza tras la inserción al sector productivo de la economía.

Asimismo, se constató que el determinante de naturaleza social más importante de la migración de la región recae en lo referente a la acumulación de capital humano y la búsqueda de retornos más altos, En este contexto, la región debe definir políticas educativas que converjan en 
el largo plazo hacia la denominada Knowledge Economy (Economía del Conocimiento) que plantea que las características de la dinámica de la innovación y del desarrollo tecnológico en los países la información y el conocimiento son utilizados, como parte de la cadena de valor, haciendo que estos se conviertan en productos y servicios también en mejoría de las condiciones de vida de la población. Los países desarrollados y de ingresos más altos a los que suelen dirigirse los flujos de emigrantes suelen ser de este tipo, ya que el conocimiento es vital en la generación de valor y riqueza (Aragonés Castañer \& Salgado Nieto, 2011).

En este particular se hace referencia explícita al largo plazo, ya que es importante considerar que los países de la región, tanto por cuestiones estructurales y propias de su composición en el contexto histórico, se encuentran bastantes distantes de alcanzar las capacidades acumuladas que propician la economía de conocimiento, aunque estos han exhibido mejora en el campo de la ciencia y la producción como han evidenciado los países Iberoamericanos (CEPAL, 2008).

Finalmente, dado el alcance de este estudio se sugiere a futuras investigaciones realizar un análisis por separado de las causas y determinantes de este fenómeno en cada uno de los países, debido a las diferencias existentes en lo que respecta a la situación e intereses de los países de la región SICA con relación a la migración internacional para formular políticas que resulten más efectivas y eficientes en la consecución de estos y sus propias características.

\section{Referencias}

Aguilera, A. A. (5 de Septiembre de 2020). aguilaresteva.com. Obtenido de aguilaresteva.com: http://www.aguilaresteva.com/wp-content/ uploads/2018/08/3_Efectos-Fijos-y-Efectos-Aleatorios.pdf

Alba, F. (2001). Comercio, Migración y esquemas de integración económica: los casos de la CEE y el TLCAN. México: Foro Internacional, El Colegio de México.

Alonso, J. A. (2011). Migración Internacional y desarrollo: Una revisión a la luz de la crisis. CDP Background Paper Series(11), 1-64.

Alonso, J. C., \& Muñoz, A. (2014). Interpretación de Variables Dummy en modelos log-lin. Cali, Colombia: Departamento de Economía, Universidad Icesi. 
Anderson, T. R. (Jun. de 1955). Intermetropolitan Migration: A Comparison of the Hypotheses of Zipf and Stouffer. American Sociological Review(20), 287-291.

Aragonés Castañer, A. M., \& Salgado Nieto, U. (12 de Marzo de 2015). Migración laboral México-Estados Unidos a veinte años del Tratado de Libre Comercio de América del Norte. Revista Mexicana de Ciencias Politicas y Sociales, 60(224), 279-313.

Arellano, M. (1987). Computing Robust Standars Errors for Withingroups Estimator. Oxford Bulletin of Economics and Statiscs, 49(4), 431-434.

Aruj, R. S. (2008). Causas, consecuencias, efectos e impacto de las migraciones en Latinoamérica. Papeles de Población, 14(55), 85-103. Obtenido de https://www.redalyc.org/articulo.oa?id=11205505

Baronio, A., \& Vianco, A. (2014). Datos de Panel. Argentina: Universidad Nacional de Río Cuarto.

Borjas, G. J. (1989). Economic Theory and International Migration. The International Migration Review, 23(3), 457-485.

Borjas, G. J. (Oct. de 1999). Immigration and Welfare Magnets. Journal of Labor Economics, 17(4), 607-637.

Boyd, M. (1 de Junio de 1989). Family and Personal Networks in International Migration: Recent Developments and New Agendas. The International Migration Review, 638-670.

Burridge, P., \& Gordon, I. (Jul. de 1981). Unemployment in the British Metropolitan Labour Areas. Oxford Economic Papers, 33(2), 274-297.

Bustamante, J. A. (2002). Migración internacional y derechos humanos. Serie Doctrina Jurídica(94), 1-203.

Cantillon, R. ((1755), 1996). Ensayo sobre la naturaleza del comercio en general. Distrito Federal, México: Fondo de Cultura Económica.

Carey, H. C. (1858). Principles of Social Science (Vol. I). New York: J.B. Lippincott \& Co.

Castles, S. (23 de Junio de 2010). Understanding Global Migration: A Social Transformation Perspective. Journal of Ethnic and Migration Studies, 36, 1565-1586.

Castles, S., de Haas, H., \& Miller, M. J. (2014). The Age of Migration: International Population Movements in the Modern World (Quinta ed.). Londres: Palgrave macmillan. 
Cernianski, M. (1990). MIgraciones. Barcelona, España: Editorial Tusquets.

Criales, L. (1994). Mujer y conflictos socio-culturales: el caso de las migrantes de Caquiaviri en la ciudad de La Paz. La Paz: Ediciones Aruwiyiri.

Foad, H. (2012). FDI and immigration: a regional analysis. The Annals of Regional Science, 49, 237-259.

Galvis, L. A. (Enero-Junio de 2002). Determinantes de la migración interdepartamental en Colombia 1988-1993. Revista de Economía del Rosario, 5(1), 93-118.

García-Ferrer, A. (1980). Interactions between internal migration, employment growth, and regional income differences in Spain. Journal of Development Economics, 7(2), 211-229.

Geddes, A., \& Scholten, P. (2016). The Politics of Migration and Immigration in Europe (Segunda ed.). Londres: SAGE Pubkications Ltd.

Gordon, I., \& Vickerman, R. (August. de 1982). Opportunity, Preference and Constraint: an Approach to the Analysis of Metropolitan Migration. SAGE Journals, 247-261.

Granados, R. M. (Jun. de 2011). Efectos fijos o aleatorios: test de especificación. Documentos de Trabajo en Economía Aplicada, 1-5.

Greene, W. H. (2003). Econometric Analysis (5th ed.). New Jersey: Hall/ Pearson.

Greenwood, M. J. (Jun. de 1975). Research on Internal Migration in the United States: A Survey. Journal of Economic Literature, 13(2), 397-433.

Grimson, A. (Enero-Febrero de 1997). Relatos de la diferencia y la igualdad: Los bolivianos en Buenos Aires. Nueva Sociedad(147), 96-107.

Hicks, J. R. (1932). The Theory of Wages. Londres: Macmillan Company. Hicks, J. R. (1963). The working competition. En J. R. Hicks, The Theory of Wages (págs. 58-88). Toronto: Macmillan Company.

Hinojosa Gordonava, A. R. (2009). Buscando la vida: familias bolivianas transnacionales en España. La Paz, Bolivia: Fundación PIEB/CLACSO. Hollifield, J. F. (2000). The Politics of International Migration. How Can" We Bring the State Back In"? En J. F. Hollifield, \& C. B. Brettell, Talking Across Disciplines (pág. Cap. 7). Londres: Routledge.

Hollifield, J. F., \& Brettell, C. B. (2000). Migration Theory: Talking acroos Discplines (Tercera ed.). New York: Routledge. 
Javorcik, C. (2010). Emigrant Networks and foreign direct investment. Journal of development economics, 94(2), 231-241.

Joppke, C. (1998). Immigration Challenges the Nation State. En C. Joppke, Challenge to the Nation-State. Immigration in Western Europe and the United (págs. 5-48). New York: Oxford University Press.

Kontuly, T., Smith, K. R., \& Heaton, T. B. (1995). Culture as a determinant of reasons for migration. The Social Science Journal, 32(2), 179-193.

Labra, R., \& Torrecillas, C. (2014). Guía CERO para datos de panel. Un enfoque. UAM-Accenture Working Papers(16), 1-61.

Lewis, A. W. (1954). Economic development. The Manchester School, 22(2), 139-191.

Maric Palenque, M. L. (2009). ¿Por qué migramos?: Representaciones y factores psicológicos de la migración. Murillo, Bolivia: Instituto de Estudios Bolivarianos.

Marmora, L. (1990). La migración en los procesos regionales y subregionales de integración en América del Sur. Revista sobre Migraciones en América Latina de la Oganización Internacional para las Migraciones (OIM).

Massey, D. S., \& García, F. E. (Aug. de 1987). The Social Process of International Migration. American Association for the Advancement Science, 237(4816), 733-738.

Massey, D. S., Arango, J., Graeme, H., Kouaouci, A., Pellegrino, A., \& Taylor, E. J. (1993). Theories of International Migration: A Review and Appraisal. Population and Development Review, 431-466.

Mayda, A. M. (2010). International migration: a panel data analysis of the determinants of bilateral flows. Journal of Population Economics, 23(4), 2149-1274.

Mayorga, M. M., \& Muñoz, E. S. (2000). La técnica de datos de panel: una guía para su uso e interpreación. Costa Rica: Banco Central de Costa Rica.

Mazurek, H. (2009). Migraciones y dinámicas territoriales. En C. Salazar, Migraciones contemporáneas: contribución al debate (págs. 11-33). La Paz, Bolivia: Plural Editores.

Molho, I. (Nov. de 1986). Theories of International Migration: A Review and Appraisal. Scottish Journal of Political Economy, 60(5), 396-419. 
Navarro Chávez, J. C., Ayvar Campos, F. J., \& Zamora Torres, A. I. (2016). Economic development and migration in Latin America, 1980-2013: A Study from Data Envelopment Analysis. Travaux et Recherches dans les Amériques du Centre (Trace), 70, 149-164.

Neumayer, E. (Sep. de 2005). Bogus Refugees? The Determinants of Asylum Migration to Western Europe. International Studies Quartely, 49(3), 389-409.

Pellegrino, A. (2000). Migrantes latinoamericanos y caribeños: sintésis histórica y tendecias recientes. Santiago de chile: CEPAL/CELADE.

Pellegrino, A. (2003). La migración internacional en América Latina y el Caribe: tendencias y perfiles de los migrantes. Santiago de Chile: Centro Latinoamericano y Caribeño de Demografía (CELADE).

Persky, J. J., \& Kain, J. F. (Jan. de 1970). Migration, Employment, and Race in the Deep South. Southern Economic Journal, 36(3), 268-276. Piore, M. J. (1979). Birds of Passage: Migrant Labor and Industrial Societies. Cambridge: Cambridge University Press.

Portes, A. (1997). Immigration Theory for a New Century: Some Problems and Opportunities. The international Migration Review, 31(4).

Portes, A. (2005). Convergencias teóricas y evidencias empíricas en el estudio del transnacionalismo de los inmigrantes. Migración y Desarrollo, 4, 2-19.

Portes, A. (2009). Migración y desarrollo: una revisión conceptual de la evidencia. En C. Salazar, MIgraciones Contemporáneas: contribución al debate (págs. 327-344). La Paz, Bolivia: Plural Editores.

Ravenstein, E. (Jun. de 1885). The Laws of Migration. Journal of the Statistical Society of London, 48(2), 167-235.

Rogers, A., \& Castro, L. J. (1982). Patrones Modelo de Migración. México: El Colegio de México.

Roncken, T., Alquizalet, O., Cielo, C., Céspedes, R., \& Serrudo, Y. (2009). La Vecindad que no viajó. Migración Internacional y desarrollo comunitario en zonas periurbanas de Cochabamba. La Paz: PIEB.

Roodman, D. (May de 2008). A Note on the Theme of Too Many Instruments. Center for Global Development(125), 1-38.

Rosen, S. (1986). The Theory of Equalizing Differences. En O. C. Ashenfelter, \& R. Layard, Handbook of Labor Economics (Vol. I, págs. 641-692). North Holland, Amsterdam. 
Santel, B. (Feb. de 1995). Migration in und nach Europa. Erfahrungen. Strukturen. Politik (Vol. 6). Leske + Budrich.

Schwartz, A. (1973). Interpreting the Effect of Distance on Migration. Journal of Political Economy, 5, 153-1169.

Silva, S. P. (Abr. de 2019). Determinantes para la migración internacional de colombianos entre 1990-2015 a partir de un modelo gravitacional. Revista de la Universidad del Rosario, 41, 69-100.

Sistema de la Integración Centroamericana (SICA). (8 de Febrero de 2021). Obtenido de SICA: https://www.sica.int/sica/propositos

Sjaastad , L. A. (1962). The Costs and Returns of Human Migration. En The Journal of Political Economy (Vol. 5, págs. 80-93). Chicago: University of Chicago Press.

Smith, A. ((1776), 1979). Investigación sobre la Naturaleza y Causas de las Riquezas de las Naciones. Distrito Federal. México: Fondo de Cultura Económica.

Solimano, A. (2003). Globalización y migración internacional: la experiencia latinoamericana. Revista CEPAL, No. 80, 55-72. Obtenido de https://repositorio.cepal.org/handle/11362/10895

Suval, E. M., \& Hamilton, C. H. (May de 1965). Some New Evidence on Educational Selectivity in Migration to and From the South. Soicial Forces, 43(4), 536-547.

Tajfel, H. (1981). Human groups and social categories: Studies in Social Psychology. Cambridge: Cambridge.

Todaro, M. (1969). A model of labor migration and urban unemployment in less develops countries. The American Economic Review, 59(1), 138-148.

Todaro, M. P. (1976). Internal Migration in Developing Countries: A Review of Theory, Evidence, Methodology and Research Priorities. Geneva: International Labour Office .

United Nations, Department of Economic and Social Affairs. (December de 2017). https://www.un.org/. Recuperado el Marzo de 2020, de https:/www.un.org/: https://www.un.org/en/development/desa/ population/migration/data/estimates2/data/UN_MigrantStockTotal_2017.xlsx 
Vezzoli, S., \& Flahaux, M. L. (Sep. de 2016). How do post-colonial ties and migration regimes shape travel visa requirements? The case of Caribbean nationals. Journal of Ethnic an migration Studies, 43(7), 1141-1163.

Weil, P. (16 de Diciembre de 2002). Towards a Coherent Policy of Co-Development. Internationa Migration, 40(3), 41-55.

Weinstein, E. (Apr. de 1974). Some characteristics of owner-occupier migrant households-A study based on building society data. Journal Regional Studies, 9(2), 147-156.

Zolberg, A. R. (Jan. de 1981). International Migration in Political Perspective. International Migration Review, 3-27. 


\section{Anexos}

Anexo 1. Número de emigrantes según país de origen por quinquenio

\begin{tabular}{ccccccc}
\hline Año & $\mathbf{1 9 9 0}$ & $\mathbf{1 9 9 5}$ & $\mathbf{2 0 0 0}$ & $\mathbf{2 0 0 5}$ & $\mathbf{2 0 1 0}$ & $\begin{array}{c}\text { Prom. } \\
\mathbf{2 0 1 5 - 2 0 1 7}\end{array}$ \\
\hline Belice & 36,114 & 41,978 & 48,155 & 51,826 & 57,281 & 62,387 \\
\hline Costa Rica & 69,724 & 85,484 & 105,797 & 118,544 & 136,721 & 141,610 \\
\hline $\begin{array}{c}\text { República } \\
\text { Dominicana }\end{array}$ & 456,259 & 664,471 & 886,144 & $1,009,332$ & $1,173,134$ & $1,411,396$ \\
\hline El Salvador & $1,241,877$ & 933,125 & 949,091 & $1,118,900$ & $1,337,703$ & $1,539,825$ \\
\hline Guatemala & 343,623 & 457,382 & 578,503 & 736,531 & 924,525 & $1,102,701$ \\
\hline Honduras & 156,553 & 246,826 & 342,259 & 449,102 & 587,662 & 713,488 \\
\hline Nicaragua & 442,037 & 438,343 & 502,147 & 436,584 & 610,957 & 653,047 \\
\hline Panamá & 134,703 & 133,346 & 137,372 & 131,870 & 139,835 & 147,485 \\
\hline Total & $2,880,890$ & $3,000,955$ & $3,549,468$ & $4,052,689$ & $4,967,818$ & $5,771,940$ \\
\hline
\end{tabular}

Fuente: United Nations, Department of Economic and Social Affairs. Population Division (2017). 
Anexo 2. Estimación por Efectos Fijos

\begin{tabular}{|c|c|c|c|c|c|c|}
\hline \multirow{3}{*}{ Variables } & \multicolumn{6}{|c|}{ Ln (Número de emigrantes i en j/Población total i)*100,000 } \\
\hline & Esp. 1 & Esp.2 & Esp.3 & Esp.4 & Esp.5 & Esp.6 \\
\hline & (1) & (2) & (3) & (4) & (5) & (6) \\
\hline \multirow{2}{*}{$\begin{array}{l}\text { Diferencias PIB per } \\
\text { cápita entre it y jt }\end{array}$} & 0.017 & $-0.134^{* *}$ & $-0.215^{* * *}$ & $-0.213^{* * *}$ & $-0.207^{* * *}$ & $-0.207^{* * *}$ \\
\hline & $(0.045)$ & $(0.056)$ & $(0.068)$ & $(0.069)$ & $(0.069)$ & $(0.069)$ \\
\hline \multirow{2}{*}{$\begin{array}{c}\text { Ln Distancia Física } \\
\text { entre it y jt }\end{array}$} & 0.005 & $0.026^{* *}$ & 0.013 & 0.013 & 0.015 & 0.015 \\
\hline & $(0.010)$ & $(0.010)$ & $(0.012)$ & $(0.012)$ & $(0.012)$ & $(0.012)$ \\
\hline \multirow{2}{*}{ Tasa de desempleo it } & $-0.014^{* * *}$ & -0.007 & $-0.018^{* * *}$ & $-0.018^{* * *}$ & $-0.019^{* * *}$ & $-0.019^{* * *}$ \\
\hline & $(0.005)$ & $(0.005)$ & $(0.005)$ & $(0.005)$ & $(0.005)$ & $(0.005)$ \\
\hline \multirow{2}{*}{ Tasa de desempleo jt } & & $0.023^{* *}$ & -0.013 & -0.013 & -0.012 & -0.012 \\
\hline & & $(0.011)$ & $(0.013)$ & $(0.013)$ & $(0.013)$ & $(0.013)$ \\
\hline \multirow{2}{*}{ Esperanza de vida it } & & 0.006 & 0.015 & 0.014 & 0.018 & 0.018 \\
\hline & & $(0.011)$ & $(0.012)$ & $(0.012)$ & $(0.012)$ & $(0.012)$ \\
\hline \multirow{2}{*}{ Esperanza de vida jt } & & 0.007 & $0.073^{* * *}$ & $0.073^{* * *}$ & $0.065^{* *}$ & $0.065^{* *}$ \\
\hline & & $(0.020)$ & $(0.026)$ & $(0.026)$ & $(0.026)$ & $(0.026)$ \\
\hline \multirow{2}{*}{$\begin{array}{c}\text { Ańos de } \\
\text { escolarización prom. } \\
\text { it }\end{array}$} & & $0.054^{* * *}$ & $0.048^{* * *}$ & $0.048^{* * *}$ & $0.051^{* * *}$ & $0.051^{* * *}$ \\
\hline & & $(0.017)$ & $(0.018)$ & $(0.018)$ & $(0.018)$ & $(0.018)$ \\
\hline \multirow{2}{*}{$\begin{array}{c}\text { Años de } \\
\text { escolarización prom. } \\
\text { jt }\end{array}$} & & & -0.001 & -0.001 & 0 & 0 \\
\hline & & & $(0.001)$ & $(0.001)$ & $(0.001)$ & $(0.001)$ \\
\hline \multirow{2}{*}{ Indice de Gini it } & & & $0.008^{* * *}$ & $0.008^{* * *}$ & $0.009^{* * *}$ & $0.009^{* * *}$ \\
\hline & & & $(0.001)$ & $(0.001)$ & $(0.001)$ & $(0.001)$ \\
\hline \multirow{2}{*}{ Indice de Gini jt } & & & $-0.002^{*}$ & $-0.002^{*}$ & -0.001 & -0.001 \\
\hline & & & $(0.001)$ & $(0.001)$ & $(0.001)$ & $(0.001)$ \\
\hline \multirow{2}{*}{ Tasa de homicidio it } & & & $-0.007^{* * *}$ & $-0.007^{* * *}$ & $-0.007^{* * *}$ & $-0.007^{* * *}$ \\
\hline & & & $(0.002)$ & $(0.002)$ & $(0.002)$ & $(0.002)$ \\
\hline \multirow{2}{*}{ Tasa de homicidio jt } & & & & 0.065 & 0.058 & 0.058 \\
\hline & & & & $(0.101)$ & $(0.101)$ & $(0.101)$ \\
\hline \multirow{2}{*}{$\begin{array}{l}\text { Conflicto político } \\
\text { interno jt (binaria) }\end{array}$} & & & & & $-0.019^{* *}$ & $-0.019^{* *}$ \\
\hline & & & & & $(0.009)$ & $(0.009)$ \\
\hline Observaciones & & 2,035 & 1,936 & 1,671 & 1,671 & 1,671 \\
\hline $\mathbf{R 2}$ & & 0.005 & 0.075 & 0.138 & 0.138 & 0.141 \\
\hline $\mathbf{R}^{2}$ Ajustado & & -0.206 & -0.133 & -0.078 & -0.079 & -0.076 \\
\hline Estadístico F & & $\begin{array}{c}2.717^{* *} \\
(\mathrm{df}=3 ; \\
1678)\end{array}$ & $\begin{array}{c}18.206^{* * *} \\
(\mathrm{df}=7 \\
1580)\end{array}$ & $\begin{array}{c}19.422^{* * *} \\
(\mathrm{df}=11 \\
1335)\end{array}$ & $\begin{array}{c}17.830^{* * *} \\
(\mathrm{df}=12 \\
1334)\end{array}$ & $\begin{array}{c}16.857^{* * *} \\
(\mathrm{df}=13 ; \\
1333)\end{array}$ \\
\hline
\end{tabular}

Nota: los niveles de significación estadística presentados son ${ }^{* * *}$ significativo al $1 \%$; ${ }^{* *}$ significativo al $5 \%$; $\mathrm{y}^{*}$ significativo al $10 \%$. 
Anexo 3. Estimación por Efectos Aleatorios

\begin{tabular}{|c|c|c|c|c|c|c|}
\hline \multirow{3}{*}{ Variables } & \multicolumn{6}{|c|}{ Ln (Número de emigrantes $i$ en j/Población total i)*100,000 } \\
\hline & Esp. 1 & Esp.2 & Esp.3 & Esp.4 & Esp.5 & Esp.6 \\
\hline & (1) & (2) & (3) & (4) & (5) & (6) \\
\hline \multirow{2}{*}{$\begin{array}{l}\text { Diferencias PIB per } \\
\text { cápita entre it y jt }\end{array}$} & -0.042 & $-0.174^{* * *}$ & $-0.279^{* * *}$ & $-0.274^{* * *}$ & $-0.267^{* * *}$ & $-0.287^{* *}$ \\
\hline & $(0.043)$ & $(0.054)$ & $(0.063)$ & $(0.063)$ & $(0.063)$ & $(0.063)$ \\
\hline \multirow{2}{*}{$\begin{array}{c}\text { Ln Distancia Física } \\
\text { entre it y jt }\end{array}$} & $-1.215^{* * *}$ & $-1.369^{* * *}$ & $-1.576^{* * *}$ & $-1.597^{* * *}$ & $-1.594^{* * *}$ & $-1.611^{*+}$ \\
\hline & $(0.109)$ & $(0.108)$ & $(0.110)$ & $(0.105)$ & $(0.105)$ & $(0.165)$ \\
\hline \multirow{2}{*}{ Tasa de desempleo it } & 0.01 & $0.028^{* * *}$ & 0.012 & 0.01 & 0.013 & 0.013 \\
\hline & $(0.010)$ & $(0.010)$ & $(0.012)$ & $(0.012)$ & $(0.012)$ & $(0.012)$ \\
\hline \multirow{2}{*}{ Tasa de desempleo jt } & $-0.015^{* * *}$ & $-0.009^{*}$ & $-0.017^{* * *}$ & $-0.018^{* * *}$ & $-0.018^{* * *}$ & $-0.020^{* * *}$ \\
\hline & $(0.005)$ & $(0.005)$ & $(0.005)$ & $(0.005)$ & $(0.005)$ & $(0.005)$ \\
\hline \multirow{2}{*}{ Esperanza de vida it } & & 0.011 & $-0.030^{* *}$ & $-0.026^{* *}$ & $-0.024^{* *}$ & $-0.024^{* *}$ \\
\hline & & $(0.010)$ & $(0.012)$ & $(0.012)$ & $(0.012)$ & $(0.012)$ \\
\hline \multirow{2}{*}{ Esperanza de vida jt } & & $0.023^{* *}$ & $0.033^{* * *}$ & $0.036^{* * *}$ & $0.037^{* * *}$ & $0.035^{* * *}$ \\
\hline & & $(0.010)$ & $(0.011)$ & $(0.011)$ & $(0.011)$ & $(0.011)$ \\
\hline \multirow{2}{*}{$\begin{array}{l}\text { Años de escolarización } \\
\text { prom. it }\end{array}$} & & 0.006 & $0.078^{* * *}$ & $0.067^{* * *}$ & $0.062^{* *}$ & $0.064^{* *}$ \\
\hline & & $(0.019)$ & $(0.025)$ & $(0.025)$ & $(0.025)$ & $(0.025)$ \\
\hline \multirow{2}{*}{$\begin{array}{c}\text { Años de escolarización } \\
\text { prom. jt }\end{array}$} & & $0.055^{* * *}$ & $0.062^{* * *}$ & $0.055^{* * *}$ & $0.057^{* * *}$ & $0.059^{* * *}$ \\
\hline & & $(0.017)$ & $(0.018)$ & $(0.018)$ & $(0.018)$ & $(0.018)$ \\
\hline \multirow{2}{*}{ Índice de Gini it } & & & -0.001 & -0.001 & -0.000 & -0.001 \\
\hline & & & $(0.001)$ & $(0.001)$ & $(0.001)$ & $(0.001)$ \\
\hline \multirow{2}{*}{ Índice de Gini jt } & & & $0.006^{* * *}$ & $0.006^{* * *}$ & $0.007^{* * *}$ & $0.007^{* *+}$ \\
\hline & & & $(0.001)$ & $(0.001)$ & $(0.002)$ & $(0.002)$ \\
\hline \multirow{2}{*}{ Tasa de homicidio it } & & & $-0.002^{*}$ & $-0.002^{*}$ & -0.001 & -0.001 \\
\hline & & & $(0.001)$ & $(0.001)$ & $(0.001)$ & $(0.001)$ \\
\hline \multirow{2}{*}{ Tasa de homicidio jt } & & & $-0.008^{* * *}$ & $-0.008^{* * *}$ & $-0.007^{* * *}$ & $-0.007^{* *}$ \\
\hline & & & $(0.002)$ & $(0.002)$ & $(0.002)$ & $(0.002)$ \\
\hline \multirow{2}{*}{$\begin{array}{l}\text { Conflicto político } \\
\text { interno jt (binaria) }\end{array}$} & & & & 0.058 & 0.052 & 0.053 \\
\hline & & & & $(0.103)$ & $(0.103)$ & $(0.103)$ \\
\hline \multirow{2}{*}{$\begin{array}{c}\text { Visado para entrada en } \\
\text { jt (binaria) }\end{array}$} & & & & $1.263^{* * *}$ & $1.267^{* * *}$ & $1.227^{* *+}$ \\
\hline & & & & $(0.223)$ & $(0.223)$ & $(0.218)$ \\
\hline \multirow{2}{*}{$\begin{array}{l}\text { Inversión extranjera } \\
\text { directa it }\end{array}$} & & & & & $-0.016^{*}$ & $-0.016^{*}$ \\
\hline & & & & & $(0.009)$ & $(0.009)$ \\
\hline \multirow{2}{*}{$\begin{array}{l}\text { Relación colonial entre } \\
\qquad i_{t} y \text { jt (binaria) }\end{array}$} & & & & & & $3.053^{* *+}$ \\
\hline & & & & & & $(0.632)$ \\
\hline
\end{tabular}




\begin{tabular}{|c|c|c|c|c|c|c|}
\hline \multirow{3}{*}{ Variables } & \multicolumn{6}{|c|}{ Ln (Número de emigrantes i en j/Población total i)*100,000 } \\
\hline & Esp. 1 & Esp. 2 & Esp.3 & Esp.4 & Esp. 5 & Esp. 6 \\
\hline & (1) & (2) & (3) & (4) & (5) & (6) \\
\hline \multirow{2}{*}{$\begin{array}{l}\text { Proximidad lingüística } \\
\text { entre it y jt (binaria) }\end{array}$} & & & & & & -0.147 \\
\hline & & & & & & $(0.303)$ \\
\hline \multirow{2}{*}{$\begin{array}{c}\text { Bordes geográficos } \\
\text { compartidos entre it y } \\
\text { jt (binaria) }\end{array}$} & & & & & & 0.423 \\
\hline & & & & & & $(0.546)$ \\
\hline \multirow{2}{*}{ Constante } & $11.656^{* * *}$ & $9.839^{* * *}$ & $13.647^{* * *}$ & $13.039^{* * *}$ & $12.782^{* * *}$ & $13.036^{* * *}$ \\
\hline & $(0.920)$ & (1.114) & $(1.196)$ & $(1.173)$ & $(1.181)$ & $(1.692)$ \\
\hline Observaciones & 2,035 & 1,936 & 1,671 & 1,671 & 1,671 & 1,671 \\
\hline R2 & 0.053 & 0.116 & 0.184 & 0.203 & 0.205 & 0.22 \\
\hline $\mathbf{R}^{2}$ Ajustado & 0.051 & 0.112 & 0.178 & 0.196 & 0.197 & 0.211 \\
\hline Estadístico F & $112.996^{* * *}$ & $250.468^{* * *}$ & $370.946^{* * *}$ & $419.104^{* * *}$ & $422.710^{* * *}$ & $461.720^{* * * *}$ \\
\hline
\end{tabular}

Nota: los niveles de significación estadística presentados son ${ }^{* * *}$ significativo al $1 \%$; ${ }^{* *}$ significativo al $5 \%$; $\mathrm{y}^{*}$ significativo al $10 \%$. 
Anexo 4. Interpretación coeficientes de las variables explicativas en el modelo ajustado estimado por efectos aleatorios (6)

\begin{tabular}{|c|c|}
\hline $\begin{array}{l}\text { Variable } \\
\text { explicativa }\end{array}$ & Interpretación de coeficiente \\
\hline $\begin{array}{l}\text { Diferencias PIB } \\
\text { per cápita }\end{array}$ & $\begin{array}{l}\text { La reducción en una unidad porcentual en las diferencias del PIB per cápita entre el } \\
\text { país de origen y el país de destino reduce la tasa de emigrantes en un } 29.0 \% \text {. }\end{array}$ \\
\hline Distancia Física & $\begin{array}{l}\text { Un incremento de } 10 \% \text { en la distancia entre el país de origen y el país de destino } \\
\text { provoca la reducción de su tasa de emigración en un } 0.17 \% \text {. }\end{array}$ \\
\hline $\begin{array}{l}\text { Tasa de } \\
\text { desempleo }\end{array}$ & $\begin{array}{l}\text { El aumento en una unidad porcentual en la tasa de desempleo del país receptor } \\
\text { provoca la reducción de su número de inmigrantes en un } 2.0 \% \text {. }\end{array}$ \\
\hline $\begin{array}{l}\text { Esperanza de } \\
\text { vida }\end{array}$ & $\begin{array}{l}\text { La tasa de emigración se reduce en un } 2.8 \% \text { por cada ańo que incremente la } \\
\text { esperanza de vida en el país de origen, mientras que un incremento de igual } \\
\text { magnitud en la esperanza de vida del país de destino provoca el incremento en su } \\
\text { movilidad de inmigrantes un } 3.5 \% \text {. }\end{array}$ \\
\hline $\begin{array}{l}\text { Años de } \\
\text { escolarización } \\
\text { prom. }\end{array}$ & $\begin{array}{l}\text { La tasa de emigrantes del SICA hacia los países receptores aumenta en un } 6.4 \% \\
\text { por cada ańo adicional de escolaridad que se evidencie en estos. Igualmente, se } \\
\text { presenta una relación positiva y en el caso se los países receptores por lo que un año } \\
\text { adicional de escolaridad en estos se traduce en un aumento de } 6.0 \% \text { sobre su flujo } \\
\text { de inmigrantes. }\end{array}$ \\
\hline Índice de Gini & $\begin{array}{l}\text { El aumento en una unidad en el índice de Gini en el país receptor acrecienta su } \\
\text { número de inmigrantes de la región SICA en } 0.7 \text { \%. La población migrante de los } \\
\text { países del SICA no parecen considerar la desigualdad en la distribución del ingreso } \\
\text { como un factor relevante al momento de emigrar en sus países de origen. }\end{array}$ \\
\hline $\begin{array}{l}\text { Tasa de } \\
\text { homicidio }\end{array}$ & $\begin{array}{l}\text { El incremento en una unidad porcentual en la tasa de homicidio del país destino } \\
\text { ocasiona una reducción de las inmigraciones en un } 0.7 \% \text {. La tasa de homicidio } \\
\text { en los países de origen no parece ser un factor que considerar por la población } \\
\text { emigrante de la región. }\end{array}$ \\
\hline $\begin{array}{l}\text { Conflicto } \\
\text { Político Interno }\end{array}$ & $\begin{array}{l}\text { No se corrobora la incidencia de esta variable sobre la emigración por ausencia de } \\
\text { robustez en la variable. }\end{array}$ \\
\hline Visado & $\begin{array}{l}\text { El efecto sobre la tasa de emigración ante el requerimiento de visado en el país } \\
\text { de destino es } 10.0 \text { veces mayor que cuando no se requiere, es decir hay una } \\
\text { correspondencia positiva entre ambas variables }\end{array}$ \\
\hline $\begin{array}{l}\text { Inversión } \\
\text { extranjera } \\
\text { directa (IED) }\end{array}$ & $\begin{array}{l}\text { La tasa de emigración se reduce en } 1.6 \% \text { ante el incremento en una unidad } \\
\text { porcentual en el flujo de IED en los países de la región SICA. }\end{array}$ \\
\hline $\begin{array}{l}\text { Relación } \\
\text { colonial }\end{array}$ & $\begin{array}{l}\text { Los antecedentes coloniales compartidos entre los países de destino y los países del } \\
\text { SICA potencia el efecto positivo sobre la emigración } 4.3 \text { veces más que cuando se } \\
\text { carece de esta característica. }\end{array}$ \\
\hline $\begin{array}{l}\text { Proximidad } \\
\text { lingüística }\end{array}$ & $\begin{array}{l}\text { No resulta robusta, no pudiéndose considerar como un determinante de la } \\
\text { emigración en la región. Tiene signo contrario al sugerido en la literatura. }\end{array}$ \\
\hline $\begin{array}{l}\text { Bordes } \\
\text { geográficos }\end{array}$ & $\begin{array}{l}\text { No resulta robusta, no pudiéndose considerar como un determinante de la } \\
\text { emigración en la región. Sin embargo, presenta el signo sugerido en la literatura, } \\
\text { dado que la existencia de bordes geográficos se traduce en menos costos de } \\
\text { desplazamiento. }\end{array}$ \\
\hline
\end{tabular}

